SCIENTIFIC REPORT

\title{
Keratometry measurements in preterm and full term newborn infants
}

\author{
R Friling, D Weinberger, I Kremer, R Avisar, L Sirota, M Snir
}

Br J Ophthalmol 2004;88:8-10

\begin{abstract}
Aim: To evaluate the relation between postconceptional age and birth weight with keratometric values in preterm and full term infants.

Methods: A prospective cross sectional study was performed. The cohort included 99 infants (198 eyes) admitted to the Neonatal and Neonatal Intensive Care Units at Schneider Children's Medical Center of Israel from February to September 2002. Keratometry in the horizontal and vertical meridians was performed in both eyes of each infant by two ophthalmologists using an autokeratometer. The results were evaluated according to: postconceptual age ( $<32$ weeks, 32-36 weeks, $>36$ weeks) and birth weight (<1500 g, 1501-2500 g, >2501 g).

Results: Corneal curvature measurements decreased progressively with both postconceptual age and birth weight. At $<32$ weeks, mean (standard deviation) readings were 63.3 (3.2) diopters (D) for the horizontal meridian and 57.3 (2.6) $D$ for the vertical meridian; corresponding values at $>36$ weeks were 54.0 (3.0) D and 50.7 (2.4) D. In the $<1500 \mathrm{~g}$ group, mean (SD) readings were 61.3 (3.9) D for the horizontal meridian and 56.0 (2.9) D for the vertical meridian; corresponding values in the $>2501 \mathrm{~g}$ group were 51.3 (2.1) D and 48.6 (1.8) D.

Conclusions: There is an inverse relation of horizontal and vertical keratometric values with both postconceptional age and birth weight. Highest readings were noted in the babies with the lowest birth weight and youngest postconceptional age. The decrease in corneal dioptric power to normal values is linear and is apparently part of the normal ocular maturation.
\end{abstract}

\footnotetext{
nfants born prematurely are at high risk of impaired visual acuity, refractive errors, strabismus, and other ocular problems. Numerous refraction studies in preterm infants have shown a predisposition to childhood myopia very early in life. ${ }^{1}$ However, the underlying mechanism is not well understood. Various factors contribute to the refractive status in this population, such as lower depth of the anterior chamber and higher refractive power of the lens. ${ }^{1-5}$ Several early studies also pointed to a possible role of corneal refractive power, ${ }^{2}$ which was further substantiated by the keratometry study of Gallo and Fagerholm ${ }^{3}$ comparing myopic preterm infants and emmetropic and myopic full term infants.

In this study, the relation of the corneal curvature with postconceptional age (PCA) and birth weight (BW) is evaluated in preterm and full term infants.
}

\section{MATERIALS AND METHODS}

The study sample included 99 consecutive infants (198 eyes) admitted to the Neonatal and Neonatal Intensive Care Units of Schneider Children's Medical Center of Israel from February to September 2000. Exclusion criteria were ROP stage II or higher with plus disease, neurological disease, or any syndromes. PCA was calculated by adding the actual age of the infants at the time of the ocular measurements to the gestational age in weeks, according to the criteria of Dubowitz et al. ${ }^{6}$ The ophthalmologic examination was performed after stability was achieved. Infants underwent one examination of each eye by two paediatric ophthalmologists (RF and MS), and only similar measurements by both of them were included in the study. Two drops of localine (benoxinate $\mathrm{HCl} 0.4 \%$, Fischer Pharmaceuticals, Israel) were instilled, and a neonatal Barraquer wire speculum (Storz Ophthalmic Instruments, USA) was used to open the lids. To ensure that the lid speculum would have no effect on the keratometry readings, we used a dual technique, as follows: localine drops were instilled twice to keep the babies calm and two paediatric ophthalmologists participated in the ophthalmic examination, one holding the baby and gently raising the speculum to prevent pressure on the eye, and the other performing the keratometric examination itself. The cornea was kept moist with balanced salt solution. The corneal curvature was measured in the horizontal and vertical medians with an autokeratometer (Nidek KM 500, Japan).

The study protocol was approved by the Institutional Ethics Committee (Helsinki), and informed consent was obtained from the parents.

The data were analysed using BMDP. ${ }^{7}$ Analysis of variance (ANOVA) with Bonferroni correction for multiple comparisons was used to compare groups. Pearson's correlation was calculated to determine the correlation between the keratometric values and BW and PCA. A p value of $\leqslant 0.05$ was considered significant.

After applying ANOVA to the data, we performed multiple comparisons. Each pair-wise comparison yielded a p value of $<0.001$ for the keratometric measurements by both BW group and PCA group.

\section{RESULTS}

There were 52 males and 47 females. Mean gestational age, BW, and PCA are presented in table 1 Mean horizontal and vertical corneal meridians for the right and left eyes are presented in table 2. As no significant differences were detected between the right and left eyes, we used the mean values of both eyes for the analyses. There was a highly significant correlation between the vertical and horizontal meridians $(\mathrm{r}=0.92, \mathrm{p}<0.001)$.

Table 3 presents the keratometry readings of the horizontal and vertical corneal meridians and the calculated difference between them $(\Delta \mathrm{HV})$ by BW and PCA.

Mean (SD) horizontal meridian in the lowest BW group was 61.3 (3.9) diopters (D), and mean vertical meridian, 56.0 (2.9) D. Values were lower in the $1501-2500 \mathrm{~g}$ group (horizontal meridian 56.8 (2.3) D, vertical meridian 52.7 


\begin{tabular}{|lll|}
\hline \multicolumn{2}{l}{ Table 1 Study population } \\
\hline & Mean (SD) & Range \\
\hline Gestational age (weeks) & $31.6(4.4)$ & $24-40$ \\
Birth weight (g) & $1600(750)$ & $570-4400$ \\
Postconceptional age (weeks) & $34.2(3.9)$ & $24.4-42.8$ \\
\hline
\end{tabular}

(1.9) D) and lowest in the $>2500$ g group (51.3 (2.1) D and 48.6 (1.8) D, respectively) ( $\mathrm{p}<0.001$ for both). There was also a significant decline in $\Delta \mathrm{HV}$ with increase in $\mathrm{BW}(\mathrm{p}<0.001)$.

Infants less than 32 weeks PCA had high keratometry values; mean horizontal meridian was 63.3 (3.2) D, and mean vertical meridian, $57.3(2.6) \mathrm{D}$. Corresponding values in the 32-36 week group were 58.3 (3.0) D and 53.9 (2.5) D, and in the $>36$ week group, 54.0 (3.0) D and $50.7(2.4) \mathrm{D}(\mathrm{p}<0.001$ for both). The decline in the mean horizontal and vertical meridians $(\Delta \mathrm{HV})$ with age was highly significant $(\mathrm{p}<0.001)$.

\section{DISCUSSION}

At birth, the globe is larger in its transverse diameter than in its sagittal diameter (mean $18.3 \mathrm{~mm}$ ); the vertical diameter measures $17.3 \mathrm{~mm}$. In preterm infants, the sagittal and transverse diameters are nearly identical, and the vertical diameters are smaller.

The horizontal and vertical corneal diameters at birth are high (approximately $10 \mathrm{~mm}$ ) relative to the adult eye, attaining adult size at ages $1-3$ years. ${ }^{8}$ The period of most rapid corneal growth is the first six months of life. The newborn cornea is also steeper than the adult cornea, and is usually more curved in its periphery than centrally. ${ }^{9}$ The mean radii of the curvature of the anterior and posterior surfaces of the human cornea are 7.8 and $6.5 \mathrm{~mm}$, respectively, compared with the radius of the external surface of the scleral globe, which measures $11.5 \mathrm{~mm}$. The radii of the corneal curvature translate into a vergence of power of approximately $48.8 \mathrm{D}$, which accounts for three quarters of the total refractive power of the eye. ${ }^{10}$

Many studies on the radius of the corneal curvature in newborns and infants have been published, but the results vary owing to the technical difficulties of using a keratometer while the babies are moving. Ehlers et al reported a mean value of $53.13 \mathrm{D}$ for preterm infants, $47.50 \mathrm{D}$ for full term infants, and $43.69 \mathrm{D}$ for children aged $2-4$ years. ${ }^{11}$ Donzis et al found the corneal curvature to be about $60 \mathrm{D}$ at 28 weeks' gestational age; at term, the mean curvature was about 51 D. ${ }^{12}$ In preterm infants, there was reduction of about $8 \mathrm{D}$ in the corneal curvature in the last three months of gestation. The authors concluded that the radius of corneal curvature reaches adult range at about 3 years of age. Yamamoto et al, in a trial to fit a contact lens to newborns, found that the mean corneal curvature of the preterm baby was $50.75 \mathrm{D}$, and of the full term baby, $48.06 \mathrm{D} .^{13}$ In a study of preterm babies aged 2-12 weeks, Yuji reported a rapid corneal curvature change (from 49.01 to $45.98 \mathrm{D}$ ) during the first two to four weeks of life, followed by a deceleration after eight weeks $(44.60 \mathrm{D}) .{ }^{14}$ Regardless of gestational age at birth, the power of the corneal curvature rapidly decreased and reached normal childhood range within 12 weeks. ${ }^{14}$ Our results in preterm and term babies are very similar to those of Ehlers et $a l^{11}$ and Yamamoto et al. ${ }^{13}$ However, in our study we recorded both horizontal and vertical keratometry powers and noted that both BW and PCA played an important role. The lower the BW and PCA, the higher the horizontal, vertical, and $\Delta$ HV values.

Hittner et al ${ }^{15}$ and Gallo and Fagerholm ${ }^{3}$ found an association between high keratometric values and retinopathy of prematurity (ROP). They emphasised the pathogenic
Table 2 Horizontal and vertical meridians of the right and left eyes

\begin{tabular}{lll}
\hline & $\begin{array}{l}\text { Right eye } \\
\text { (mean (SD)) }\end{array}$ & $\begin{array}{l}\text { Left eye } \\
\text { (mean (SD)) }\end{array}$ \\
\hline \begin{tabular}{lll} 
Horizontal meridian (D) & $58.6(5.0)$ & $58.6(5.0)$ \\
Vertical meridian (D) & $53.8(3.9)$ & $54.2(3.5)$ \\
\hline$p=0.24$ for right eye $v$ left eye. & \\
$p<0.001$ for vertical $v$ horizontal meridian.
\end{tabular} \\
\hline
\end{tabular}

importance of high corneal refractive power in the development of myopia in preterm children. However, the relative weight of each of the refractive elements-namely, corneal curvature, depth of the anterior chamber, lens thickness, and axial length-remains controversial.

There is a general consensus that the degree and frequency of myopia are proportional to changes in the cicatricial retinopathy, ${ }^{16}{ }^{17}$ but there still remains disagreement regarding the refractive abnormalities in eyes in which the ROP disappears spontaneously. Some authors have found that the degree and frequency of myopia in these cases were similar to those in eyes without ROP. ${ }^{18}{ }^{19}$ Others have claimed that the frequency of myopia was high in preterm infants regardless of ROP. ${ }^{2021}$ Quinn et al found that refractive status in prematurely born infants changed to myopia between the ages of 3 months and 1 year, but not thereafter. ${ }^{22}$ Therefore, they assumed that in preterm infants, myopia could be predicted by the refractive findings at 3 months of age. In our study, only babies with ROP stage I-II without plus disease were included. Therefore, we did not find an association between ROP stage and keratometric values.

Astigmatism occurs more frequently in the neonatal period than later in life and has a different axis. Fulton et al examined 75 infants under 1 year of age and noted astigmatism greater than $1 \mathrm{D}$ in $19 \%{ }^{23}$ In a related study, ${ }^{24}$ they noted a relationship between astigmatism and higher degrees of myopia, and suggested that the more severe larger astigmatism may contribute to the development of myopia by the visual blurring mechanism found in animals. Rutstein et al noted that extremely premature infants tended to have more myopia and greater astigmatism than infants born closer to term. ${ }^{25}$

Fielder et al postulated that lower extrauterine temperatures may impede corneal flattening in preterm infants. ${ }^{26}$ However, other studies have found that normal ocular development and emmetropisation are apparently dependent on regulatory mechanisms in the retina and central nervous

Table 3 Horizontal and vertical corneal meridians by various parameters

\begin{tabular}{|c|c|c|c|}
\hline & $\begin{array}{l}\text { Horizontal } \\
\text { meridian (H) } \\
\text { (mean (SD)) }\end{array}$ & $\begin{array}{l}\text { Vertical } \\
\text { meridian (V) } \\
\text { (mean (SD)) }\end{array}$ & $\begin{array}{l}\underset{\mathrm{HV}}{(\mathrm{SD}))} \\
\text { (mean }\end{array}$ \\
\hline \multicolumn{4}{|l|}{ Birth weight (g) } \\
\hline$\leqslant 1,500(n=56)$ & $61.3(3.9)$ & $56.0(2.9)$ & $5.3(2.0)$ \\
\hline $1500-2500(n=30)$ & $56.8(2.3)$ & 52.7 (1.9) & $4.1(1.5)$ \\
\hline$>2,500(n=13)$ & $51.3(2.1)$ & $48.6(1.8)$ & $2.7(1.2)$ \\
\hline $\begin{array}{l}\text { Significance of } \\
\text { difference }\end{array}$ & $p<0.001$ & $p<0.001$ & $p<0.001$ \\
\hline \multicolumn{4}{|l|}{$\begin{array}{l}\text { Postconceptional age } \\
\text { (weeks) }\end{array}$} \\
\hline$\leqslant 32(n=32)$ & $63.3(3.2)$ & $57.3(2.6)$ & $6.0(1.8)$ \\
\hline $32-36(n=37)$ & $58.3(3.0)$ & $53.9(2.5)$ & $4.4(1.9)$ \\
\hline$>36(n=30)$ & $54.0(3.0)$ & $50.7(2.4)$ & $3.3(1.2)$ \\
\hline $\begin{array}{l}\text { Significance of } \\
\text { difference }\end{array}$ & $p<0.001$ & $\mathrm{p}<0.001$ & $\mathrm{p}<0.001$ \\
\hline
\end{tabular}


system. ${ }^{27}$ Wildsoet and Pettigrew gave chickens intravitreal injections of kainic acid and found that higher doses induced corneal flattening which stopped the myopic shift associated with the expansion of the vitreal chamber. ${ }^{28}$ Nevertheless, in some of the eyes given a low dose, the corneal steepening caused a myopic shift, which was opposed by the effects of the increase in cornea-lens separation without an accompanying increase in axial length. Therefore, it is possible that in preterm children, the development of retinal lesions leads to similar effects on eye growth and refractive changes. Chemical elements may affect corneal steepening, expansion of the vitreal chamber, and cornea-lens separation.

In conclusion, our study revealed an inverse relationship of horizontal and vertical keratometric readings, and the difference between them, with PCA and BW. Babies with the lowest BW and PCA had the highest keratometric readings. The decrease in corneal dioptric power toward normal values with the increase in BW and PCA is linear, in accordance with other maturation parameters, and it is probably part of the normal ocular maturation process, along with the increase in eyeball dimensions.

\section{ACKNOWLEDGEMENTS}

We would like to thank Gloria Ginzach and Hanni Penn for their editorial and secretarial assistance, and Pnina Balilus for the statistical calculations.

\section{Authors' affiliations}

R Friling, M Snir, Schneider Children's Medical Center, Department of Ophthalmology, Petah Tiqva, Israel

L Sirota, Department of Neonatology, Schneider Children's Medical Center of Israel

D Weinberger, I Kremer, R Avisar, Department of Ophthalmology, Rabin Medical Center, Beilinson Campus, Petah Tiqva and Sackler Faculty of Medicine, Tel Aviv University, Tel Aviv, Israel

Correspondence to: R Friling, Department of Ophthalmology, Schneider Children's Medical Center of Israel, 14 Kaplan Street, Petah Tiqva 49 202, Israel; friling@netvision.net.il

\section{REFERENCES}

1 Fledelius H, Prematurity and the eye. Ophthalmic 10-year follow-up of children of low and normal birthweight. Acta Ophthalmol 1976; 128(Suppl):3-245.

2 Yamamoto $M$, Tatsugami $H$, Bun J. A follow-up study of refractive errors in premature infants. Jpn J Ophthalmol 1979;23:435-43.

3 Gallo JE, Fagerholm P. Low-grade myopia in children with regressed retinopathy of prematurity. Acta Ophthalmol, (Copenh), 1993;71:519-23.
4 Koraszewska-Maruszewska B, Samochowiec-Donocik E, Pieczara E, et al Myopia as a complication of retinopathy of prematurity. Klin Oczna 1993;95:339-42.

5 Gordon RA, Donzis PB. Myopia associated with retinopathy of prematurity. Ophthalmology 1986;93:1593-8.

6 Dubowitz LMS, Dubowitz V, Goldberg C. Clinical assessment of gestational age in newborn infants. J Pediatr 1970;77:1-10.

7 BMDP Statistical Software, Dixon WJ, ed. Los Angeles: University of California Press, 1992.

8 Karesh JW. Topographic anatomy of the eye: an overview. In: Tasman W, Jeager EA, eds. Duane's Foundations of Clinical Ophthalmology. Philadelphia: JB Lippincott, 1994:1-30.

9 Gordon RA, Donzis PB. Refractive development of the human eye. Arch Ophthalmol 1985;103:785-9.

10 Smolek MK, Klyce SD. Cornea. In: Tasman W, Jeager EA, eds. Duane's Foundations of Clinical Ophthalmology. Philadelphia: JB Lippincott, 1994: 1-20.

11 Ehlers N, Sorensen T, Bramsen, et al. Control corneal thickness in newborns and children. Acta Ophthalmol 1976;54:285-90.

12 Donzis PB, Insler MS, Gordon RA. Corneal curvature in premature infants. Am J Ophthalmol 1985;99:213-15.

13 Yamamoto M, Bun J, Okuda T. Corneal curvature in children. J Jpn Contact Lens Soc 1981:23:89-92.

14 Yuji I. The rapid change of corneal curvature in the neonatal period and infancy. Arch Ophthalmol 1986;104:1026-7.

15 Hittner H, Rhodes L, McPherson A. Anterior segment abnormalities in cicatricial retinopathy of prematurity. Ophthalmology 1979;86:803-16.

16 Nissenkorn I, Yassur Y, Mashkowski D, et al. Myopia in premature babies with and without retinopathy of prematurity. BrJ Ophthalmol 1983;67:170-3.

17 Robinson R, O'Keefe M. Follow up study on premature infants with and without retinopathy of prematurity. $\mathrm{Br} J$ Ophthalmol 1993;77:91-4.

$18 \mathrm{Kim}$ JY, Kwak SI, Yu YS. Myopia in premature infants at the age of 6 months. Korean J Ophthalmol 1992;6:44-9.

19 Schaffer DB, Quinn GE, Johnson L. Sequelae of arrested mild retinopathy of prematurity. Arch Ophthalmol 1984;102:373-6.

20 Fledelius HC. Pre-term delivery and subsequent ocular development. A 7-10 year follow-up of children screened 1982-84 for ROP 3. Refraction. Myopia of prematurity. Acta Ophthalmol Scand 1996;74:297-300.

21 Holmström G, Azazi M, Kugelberg U. Ophthalmological long-term follow up of preterm infants: a population-based, prospective study of the refraction and its development. Br J Ophthalmol 1998;82:1265-71.

22 Quinn GE, Dobson V, Kivlin J, et al. Cryotherapy for Retinopathy of Prematurity Cooperative Group. Prevalence of myopia between 3 months and $51 / 2$ years in preterm infants with and without retinopathy of prematurity. Ophthalmology 1998;105:1292-300.

23 Fulton $A B$, Dobson V, Salem D, et al. Cycloplegic refractions in infants and young children. Am J Ophthalmol 1980;239:239-41.

24 Fulton AB, Hansen RM, Petersen RA. The relation of myopian and astigmatism in developing eyes. Ophthalmology 1982;89:298-302.

25 Rutstein RP, Wesson GD, Gotlieb S, et al. Clinical comparison of the visual parameters in infants with intrauterine growth retardation vs. infants with normal birth weight. Am J Optom Phys Optics 1986;63:697-701.

26 Fielder A, Levene M, Russell-Eggitt I, et al. Temperature-a factor in ocular development. Dev Med Child Neurol 1986;28:279-84

27 Raviola E, Wiesel T. Neural control of eye growth and experimental myopia in primates. Ciba Foundation Symposium, 155. In: Myopia and the Control of Eye Growth. Chichester: Wiley \& Sons, 1990:22-44.

28 Wildsoet C, Pettigrew J. Kainic acid-induced eye enlargement in chickens: differential effects on anterior and posterior segments. Invest Ophthalmol Vis Sci 1988;29:311-9. 